\title{
Response to Gizzo et al.: Electrosurgical bipolar vessel sealing for vaginal hysterectomies
}

\author{
Vasileios Pergialiotis • Dimitrios-Efthymios Vlachos
}

Published online: 24 September 2014

(C) Springer-Verlag Berlin Heidelberg 2014

\section{To the Editor}

We read with interest the comments by Gizzo et al. [1]. We understand that the interpretation of our composite morbidity indices can become quite difficult without additional in-text explanation of the included indices. We also understand that composite morbidity indices (such as minor and major intraoperative complications) represent the authors' personal point of view, as other readers might disagree with these classifications. Certain errors, however, were noticed from Gizzo et al. [1] which were corrected and presented in a forthcoming erratum.

Gizzo et al. [1] also commented that we did not consider the data about postoperative pain. In fact in our previous manuscript [2] we specifically tabulated data of visual analogue scale scores that were interpreted by the original studies in mean and standard deviation or median and variance [3-5]. We excluded two studies from this tabulation because the interpretation of pain scores was different, explaining thoroughly inside our manuscript the actual reasons $[6,7]$. Furthermore, we specifically stated inside the main manuscript that in the latter two studies the pain scores were significantly lower among patients operated with an EBVS system. However, in the forthcoming erratum we will provide a meta-analysis of this index, although its interpretation should be assessed with caution as it is based on only three studies [3-5].

\footnotetext{
V. Pergialiotis · D.-E. Vlachos

1st Department of Obstetrics and Gynecology, Athens

University, Medical School, Alexandra Hospital, 80,

Vasilisis Sofias Av., 11528 Athens, Greece

V. Pergialiotis $(\bowtie)$

6, Danaidon Str., 15232 Halandri, Greece

e-mail: pergialiotis@yahoo.com
}

Conflict of interest None.

\section{References}

1. Gizzo S, Noventa M (2014) Electrosurgical bipolar vessel sealing for vaginal hysterectomies: criticism of evidences from a metaanalysis. doi:10.1007/s00404-014-3454-7

2. Pergialiotis V, Vlachos D, Rodolakis A, Haidopoulos D, Christakis D, Vlachos G (2014) Electrosurgical bipolar vessel sealing for vaginal hysterectomies. Arch Gynecol Obstet 290(2):215-222. doi:10.1007/s00404-014-3238-0

3. Cronje HS, de Coning EC (2005) Electrosurgical bipolar vessel sealing during vaginal hysterectomy. Int $\mathbf{J}$ Gynaecol Obstet 91(3):243-245. doi:10.1016/j.ijgo.2005.08.019

4. Silva-Filho AL, Rodrigues AM, de Castro Vale, Monteiro M, da Rosa DG, Pereira e Silva YM, Werneck RA, Bavoso N, Triginelli SA (2009) Randomized study of bipolar vessel sealing system versus conventional suture ligature for vaginal hysterectomy. Eur J Obstet Gynecol Reprod Biol 146(2):200-203. doi:10.1016/j. ejogrb.2009.03.014

5. Zubke W, Hornung R, Wasserer S, Hucke J, Fullers U, Werner C, Schmitz P, Lobodasch K, Hammermuller U, Wojdat R, Volz J, De Wilde RL, Wallwiener D (2009) Bipolar coagulation with the BiClamp forceps versus conventional suture ligation: a multicenter randomized controlled trial in 175 vaginal hysterectomy patients. Arch Gynecol Obstet 280(5):753-760. doi:10.1007/s00404-0091010-7

6. Lakeman MM, The S, Schellart RP, Dietz V, ter Haar JF, Thurkow A, Scholten PC, Dijkgraaf MG, Roovers JP (2012) Electrosurgical bipolar vessel sealing versus conventional clamping and suturing for vaginal hysterectomy: a randomised controlled trial. BJOG 119(12):1473-1482. doi:10.1111/j.1471-0528.2012.03484.x

7. Samulak D, Wilczak M, Michalska MM, Pieta B (2011) Vaginal hysterectomy with bipolar coagulation forceps (BiClamp) as an alternative to the conventional technique. Arch Gynecol Obstet 284(1):145-149. doi:10.1007/s00404-010-1617-8 